\title{
LOW VOLTAGE NETWORKS INSULATION MONITORING WITH TWO AND THREE VOLTMETER READOUTS METHODS
}

\begin{abstract}
Purpose. In the paper there are described methods of two and three voltmeter readouts for insulation resistance periodic measurement in live DC and AC/DC IT networks. A new measuring method for AC/DC networks is proposed. Application of a novel algorithm for shortening of measurement cycle is explained. Methodology. All methods of two and three voltmeter readouts consist in connection of a resistor and measurement of mean value of network's fixed point-to-ground voltages. Results. A new algorithm implemented in KDZ-3 device enables determination of steady-state voltage of a DC network's pole much faster than in other exploited systems. Originality. In author's modification of two voltmeter readouts method, line-to-ground voltage mean value is measured at AC side of AC/DC network. This innovation has not been applied for implementation of periodic insulation monitoring in AC/DC IT networks yet. Practical value. The use of author's innovation will allow to execute measurements at AC side of AC/DC IT networks which might be necessary if rectifier's output circuits are unavailable. Shortening of measurement cycle duration of two or three voltmeter readouts method's is of great importance in networks with high capacitance. References 8 , figures 7.
\end{abstract}

Key words: low voltage DC, AC/DC IT networks, insulation resistance, methods of two and three voltmeter readouts.

Представлено применение методов контроля изоляции сетей низкого напряжения постоянного и двойного рода тока с помощью вольтметра и резистора. Приведены формулы для вычисления сопротивления изоляции методами двух и трех отсчетов вольтметра. Предложен новый способ двух отсчетов вольтметра для сетей двойного рода тока. Представлена модификация рассматриваемых методов, ограничивающая их основной недостаток - длительность переходного процесса. Библ. 8 , рис. 7.

Ключевые слова: сети низкого напряжения постоянного и двойного рода тока, сопротивление изоляции, метод двух и трех отсчетов вольтметра.

Introduction. Insulation monitoring is of great importance for safe and reliable operation of low voltage DC and AC/DC IT networks. Periodic measurement of insulation resistance is commonly performed there with use of resistor and voltmeter. These methods are referred to as two or three voltmeter readouts (readings) methods. Three voltmeter readouts method is commonly applied in automated insulation monitoring and fault location systems Two voltmeter readouts method is simpler and produces smaller changes of conductor-to-ground voltages, but it does not enable to determine insulation resistances of single conductors.

Goal of the paper. Technical literature is short of detailed information on voltmeter readouts methods. Ways to limit the main shortcoming of these methods, i.e. long duration of transient process following connection of a resistor, have not been proposed yet. Therefore goal of the paper is to deliver a review of voltmeter readouts methods as well as to present an innovative algorithm for shortening duration of measurement. Also a new measuring procedure is proposed by author which expands capability of two voltmeter readouts method.

Two voltmeter readouts method. DC networks.

Simplest method of insulation equivalent resistance determination $R_{i}$ of DC networks exploits an additional resistor $R_{0}$. For this purpose steady-state voltages of a selected pole-to ground are measured before and after connection of the resistor between this pole and ground (Fig. 1).

Network's insulation equivalent resistance $R_{i}$ substituting resistors $R_{1}, R_{2}$ connected in parallel is given by formula

$$
R_{i}=R_{0} \cdot \frac{\left(U_{21}-U_{22}\right) \cdot R_{V}}{U_{22} \cdot\left(R_{0}+R_{V}\right)-U_{21} \cdot R_{0}},
$$

where $U_{21}$ is voltage of pole (-) without resistor $R_{0}$,
$U_{22}$ - voltage of pole (-) with resistor $R_{0}$. If voltmeter resistance $R_{V}$ meets condition $R_{V} \gg R_{0}$, then simpler formula is valid

$$
R_{i}=R_{0} \cdot \frac{U_{21}-U_{22}}{U_{22}}
$$

Insulation resistances of single poles are

$$
R_{1}=R_{i} \cdot \frac{E}{U_{21}} \text { and } R_{2}=R_{i} \cdot \frac{E}{E-U_{21}},
$$

but voltage of network source $E$ must be known.

An indispensable condition for application of this method is constant value of $E$. This requirement is in force also for other methods of voltmeter readouts.

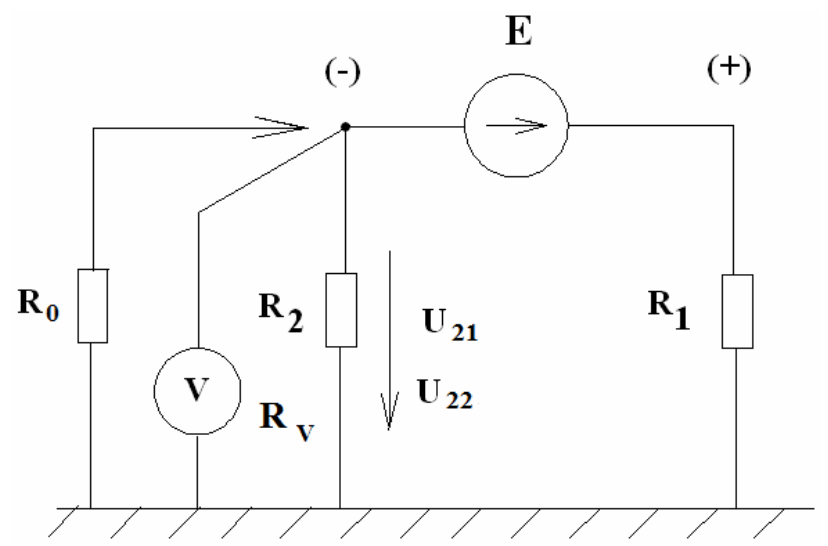

Fig. 1 Method of insulation equivalent resistance determination of DC network: $E$ - voltage of network source,

$R_{1}, R_{2}$ - insulation resistances of pole $(+)$ and $(-), R_{0}$ - resistance of additional resistor, $R_{V}-$ voltmeter resistance,

$U_{21}, U_{22}$ - voltages of pole (-) before and after connection of resistor $R_{0}$ 


\section{AC/DC networks.}

Two voltmeter readouts method can also be used in AC/DC IT system where diode rectifiers are fed by AC network (Fig. 2). This system integrates galvanically connected AC and DC circuits, both of them separated from ground (IT). Depending on location of voltage measurement two methods are available.

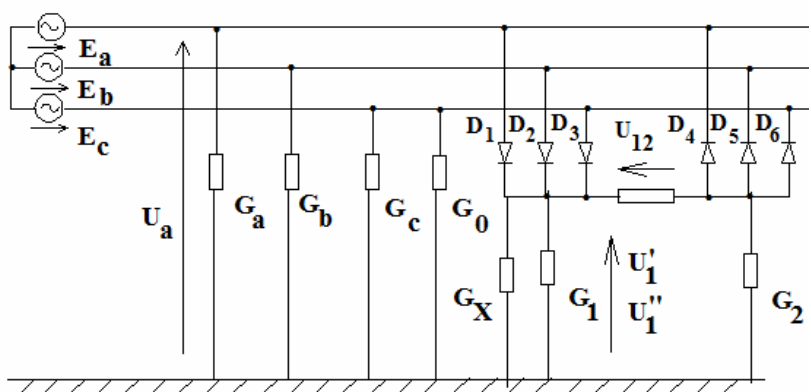

Fig. 2. AC/DC system equivalent scheme for determination of insulation resistance with use of additional conductances: $E_{a}, E_{b}$, $E_{c}$ - source phase voltages, $G_{a}, G_{b}, G_{c}$ - phase insulation conductances, $G_{0}, G_{X}$ - additional conductances, $U_{1}^{\prime}, U^{\prime \prime}{ }_{1}$ - positive pole voltages without and with conductance $G_{X}, U_{a}$ - phase «a» voltage

The first method exploits measurement of rectifier's selected pole-to-ground voltage. In this case (see Fig. 2 without $G_{0}$ ) mean values of this voltage are measured in normal operation $U_{1}^{\prime}$ (without $G_{x}$ ) and with $G_{x}$ connected between this pole and ground $U^{\prime \prime}{ }_{1}$. According to [3] these voltages are equal to

$$
\begin{gathered}
U_{1}^{\prime}=\frac{G_{a}+G_{b}+G_{c}+2 \cdot G_{2}}{G_{a}+G_{b}+G_{c}+G_{1}+G_{2}} \cdot \frac{U_{12}}{2}, \\
U_{1}^{\prime \prime}=\frac{G_{a}+G_{b}+G_{c}+2 \cdot G_{2}}{G_{a}+G_{b}+G_{c}+G_{1}+G_{2}+G_{X}} \cdot \frac{U_{12}}{2} \\
\text { From } \begin{array}{c}
\text { equations } \\
R_{i}=\frac{\text { (3) }}{G_{a}+G_{b}+G_{c}+G_{1}+G_{2}} \quad \text { (insulation }
\end{array}
\end{gathered}
$$

resistance of the whole $\mathrm{AC} / \mathrm{DC}$ system) is obtained

$$
R_{i}=R_{X} \cdot \frac{U_{1}^{\prime}-U_{1}^{\prime \prime}}{U_{1}^{\prime \prime}} .
$$

In the second method (proposed by author) [2] there is exploited characteristic feature of $\mathrm{AC} / \mathrm{DC}$ networks, i.e. mean value of phase voltage at $\mathrm{AC}$ side may be different from zero according to formula

$$
U_{a-\text { mean }}=\frac{G_{1}-G_{2}}{G_{a}+G_{b}+G_{c}+G_{1}+G_{2}} \cdot \frac{U_{12}}{2} .
$$

AC side conductor-to-ground mean voltage is measured in two states: (1) $U_{a \text { 1-mean }}$ in normal working condition, (2) $U_{\text {a2-mean }}$ with an additional resistor $R_{0}=1 / G_{0}$ connected between any conductor at $\mathrm{AC}$ side and ground. The sought parameter $G_{i}$ can be calculated from formula

$$
R_{i}=R_{0} \cdot \frac{U_{a 1-\text { mean }}-U_{a 2-\text { mean }}}{U_{a 2-\text { mean }}},
$$

which follows directly from (5).

If $\mathrm{AC}$ side-to-ground voltage has zero mean value (due to $G_{1}=G_{2}$ ), then one of $G_{1}$ or $G_{2}$ conductances should be changed by grounding artificially any selected pole through a test conductance $G_{X}$. Then both steps of the procedure described above are executed, after which the test conductance $G_{X}$ should be removed. The sought parameter $R_{i}$ is given as

$$
R_{i}=\frac{1}{\frac{1}{R_{0}} \cdot \frac{U_{a 2-\text { mean }}}{U_{a 1-\text { mean }}-U_{a 2-\text { mean }}}-\frac{1}{R_{x}}} .
$$

It should be noted that due to use of mean values of voltages, network-to-ground capacitances do not influence insulation measurement result. Therefore they are not shown at the drawing. It must be also underlined that formulas (2), (4) and (7) for two voltmeter readouts method in both types of monitored networks are identical.

\section{Three voltmeter readouts method.}

\section{DC networks.}

Three voltmeter readouts method consists of successive measurement of three voltages with voltmeter with internal resistance $R_{V}$ and connected in parallel additional resistor $R_{0}$. These steady-state voltages are measured between: $U_{12}-$ poles of DC network; $U_{1}-$ pole $(+)$ and ground; $U_{2}-$ pole $(-)$ and ground (Fig. 3 ).

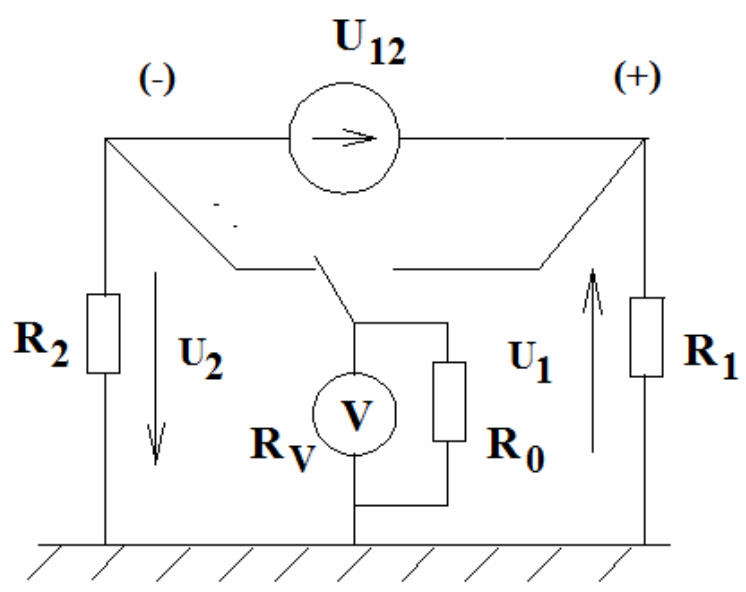

Fig. 3. Determination of DC network insulation resistance with three voltmeter readouts method: $U_{12}-$ network source voltage, $R_{1}, R_{2}$ - insulation resistance of pole ( + ) and $(-), R_{0}$ - additional resistance, $R_{V}$ - voltmeter resistance, $U_{1}$ - pole $(+)$ voltage with connected $R_{0}$ and $R_{V}, U_{2}$ - pole (-) voltage with connected $R_{0}$ and $R_{V}$

Sought value of insulation equivalent resistance $R_{i}$ is obtained from formula:

$$
R_{i}=\frac{R_{1} \cdot R_{2}}{R_{1}+R_{2}}=\frac{R_{0} \cdot R_{V}}{R_{0}+R_{V}} \cdot \frac{U_{12}-U_{1}-U_{2}}{U_{1}+U_{2}} .
$$

Resistances of single poles insulation $R_{1}$ and $R_{2}$ are:

$$
\begin{aligned}
& R_{1}=\frac{R_{0} \cdot R_{V}}{R_{0}+R_{V}} \cdot \frac{U_{12}-U_{1}-U_{2}}{U_{2}} ; \\
& R_{2}=\frac{R_{0} \cdot R_{V}}{R_{0}+R_{V}} \cdot \frac{U_{12}-U_{1}-U_{2}}{U_{1}} .
\end{aligned}
$$

It can be proved that formulas $(8)-(10)$ are true also if voltages are measured not at the poles but at any two points of the battery situated at opposite sides of its «zero» point (i.e. point with zero potential against ground). 


\section{AC/DC IT networks}

In $\mathrm{AC} / \mathrm{DC}$ IT networks three voltmeter readouts method is applied for determination of equivalent resistance of the whole system in the same way as in DC networks [4] (Fig. 3). Also in this case steady-state voltages are measured between: $U_{12}$ - poles of DC network; $U_{1}-$ pole $(+)$ and ground; $U_{2}-$ pole $(-)$ and ground. Sought value of insulation equivalent resistance $R_{i}$ is obtained from formula (8).

Examples of commercial application of three voltmeter readouts method.

DC networks insulation monitor (isometer) MD04 type. MD-04 device (manufactured by C\&T Elmech, Poland) [5] (Fig. 4) is designated for periodic measurement of insulation resistance of DC networks with nominal voltage $24,48,60,110$ or $220 \mathrm{~V}$. The device is fed by voltage of the monitored network. The measurement is executed periodically by connection of an additional resistor between ground and each pole in succession.

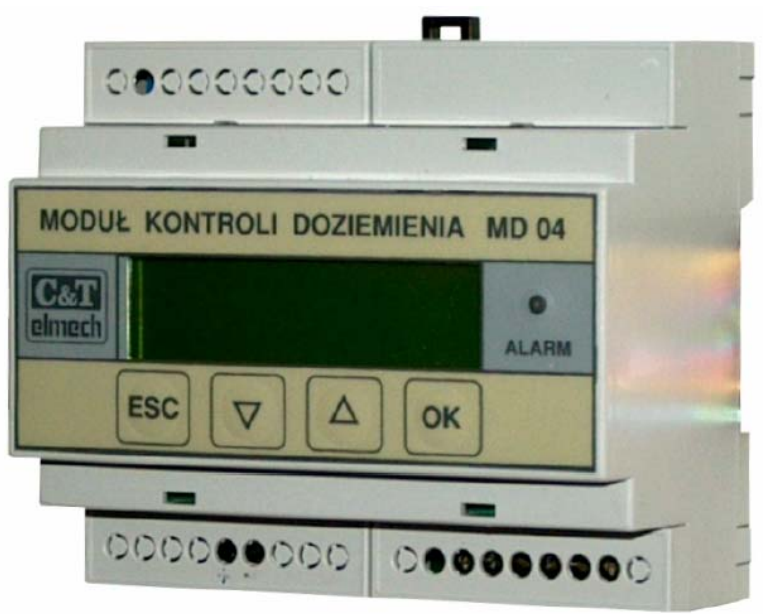

Fig. 4

Examples of waveforms of negative pole-to-ground voltage recorded during MD-04 monitor operation are shown in Fig. 5, $a, b$. It should be noted that in both cases steady-state voltages are equal because insulation resistances are the same. After each measurement cycle of both pole-to-ground voltages, a microprocessor system calculates insulation resistances which are displayed at the front panel. The isometer executes the measurement automatically immediately after connection to the network, periodically or after manual start. Measurement and calculation takes from 4 seconds to 2 minutes. In case of insulation deterioration an alarm LED is lit, then the measurement is repeated twice. If this result is confirmed, an output relay closes its contact. Information on the isometer status and insulation condition is issued also by RS485. Measurement error of MD-04 monitor does not exceed $+/-10 \%$
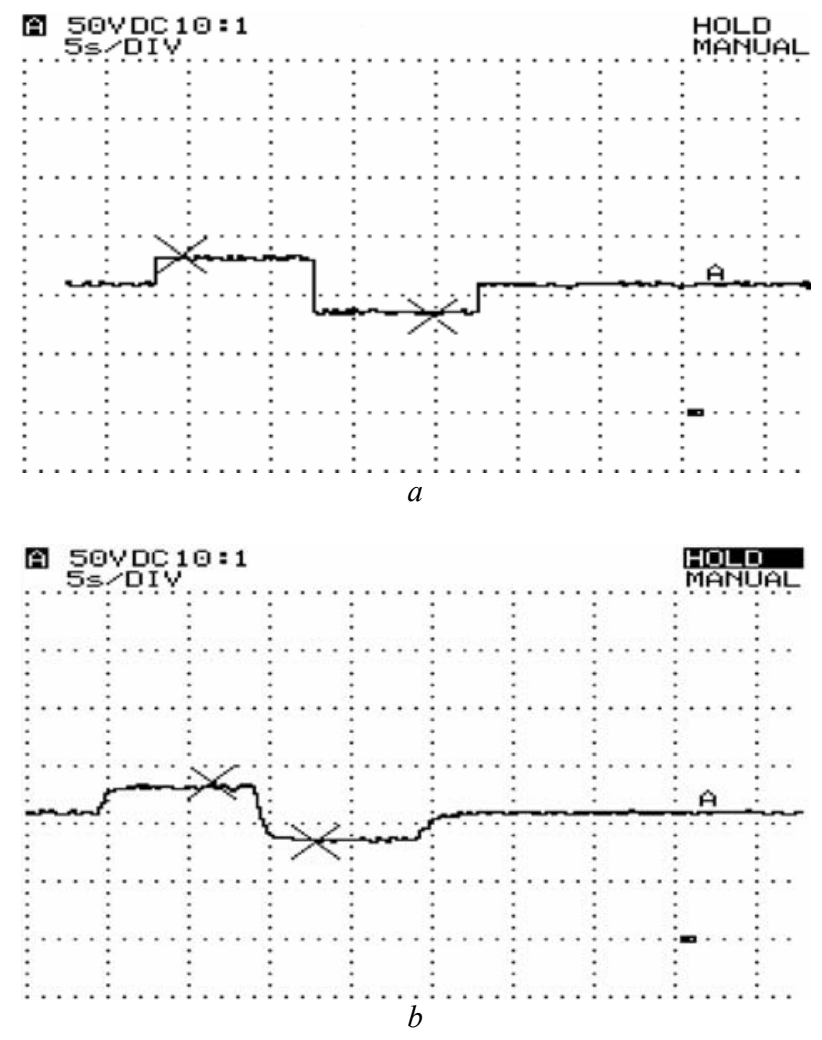

Fig. 5. Waveforms of negative pole-to-ground voltage recorded (from 85 to $130 \mathrm{~V}$ ) during MD-04 monitor's operation: $a$ ) $\mathrm{R}_{\mathrm{i}}=45$ $\left.\mathrm{k} \Omega, \mathrm{C}_{\mathrm{i}}=0 \mu \mathrm{F}, b\right) \mathrm{R}_{\mathrm{i}}=45 \mathrm{k} \Omega, \mathrm{C}_{\mathrm{i}}=20 \mu \mathrm{F}$

At Fig. 5,b attention should be turned to transient process duration about $2 \mathrm{~s}$ caused by network capacitance. Prolonged duration of this process (for high insulation capacitances and resistances it may reach even few tens of seconds) is the main shortcoming of all methods of voltmeter readouts. For its limitation a novel calculation algorithm has been implemented in insulation monitors KDZ3 type (manufactured by ZPrAE, Poland) [6, 7]. It makes it possible to determine already at initial stage the final steady-state voltage of any pole. For this purpose voltages are measured at the initial moment $y_{0}\left(t_{0}=0\right)$ and in successive moments $y_{1}\left(t_{1}\right)$ and $y_{2}\left(t_{2}\right)$ (Fig. 6).

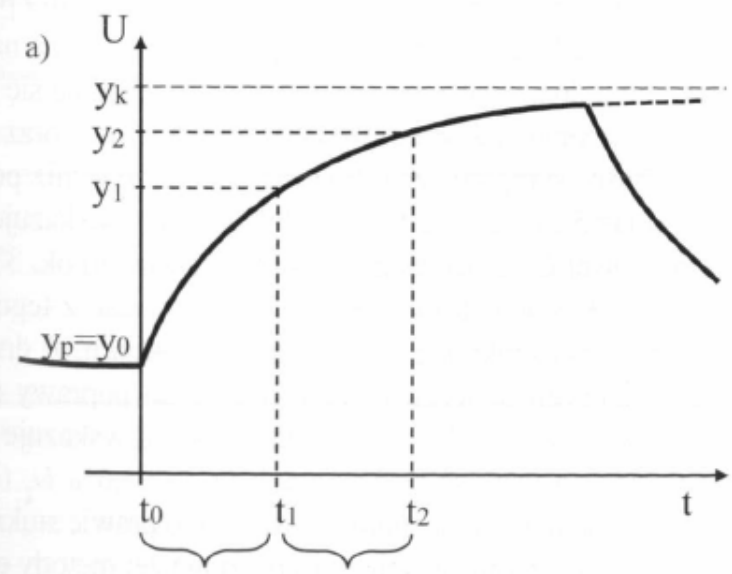

Fig. 6. Initial part of DC network pole voltage function following connection of an additional resistor to the other pole

The following formula for this voltage $y(t)$ is asumed 


$$
y(t)=y_{k}-\left(y_{k}-y_{0}\right) e^{-\frac{t}{T}},
$$

where $y_{k}, T$ - unknown parameters.

From the following equations, assuming $t_{2}=2 t_{1}$

$$
\begin{aligned}
& y_{1}=y_{k}-\left(y_{k}-y_{0}\right) e^{-\frac{t_{1}}{T}} ; \\
& y_{2}=y_{k}-\left(y_{k}-y_{0}\right) e^{-\frac{t_{2}}{T}},
\end{aligned}
$$

the sought parameter - steady-state voltage $y_{k}-$ is obtained

$$
y_{k}=\frac{y_{0} \cdot y_{2}-y_{1}^{2}}{y_{2}-2 \cdot y_{1}+y_{0}} .
$$

In this way duration of measuring cycle of devices exploiting two or three voltmeter readout method can be shortened even by $90 \%$.

DC networks insulation monitor RKI1 type. RKI1 device (manufactured by «Cheboksary Electric Apparatus Plant», Russia) [8] (Fig. 7) is designated for insulation monitoring of 110 and $220 \mathrm{~V}$ auxiliary circuits. Its functions include measurement of DC network's voltage and its variation as well as insulation resistance (equivalent and for single poles). The device fulfills signaling of parameters values outside set threshold limits. Its internal resistance is $100 \mathrm{k} \Omega$. Relative error of insulation resistance measurement does not exceed $1 \%$. Monitor can measure insulation resistance with two methods: $a$ ) three voltmeter readouts method, $b$ ) two voltmeter readouts method - insulation resistance is determined based on measured voltages of both poles against ground which are proportional to respective insulation resistances. Of course in any network there may be used only one monitor exploiting this method. This requirement relates also to monitor MD-04.

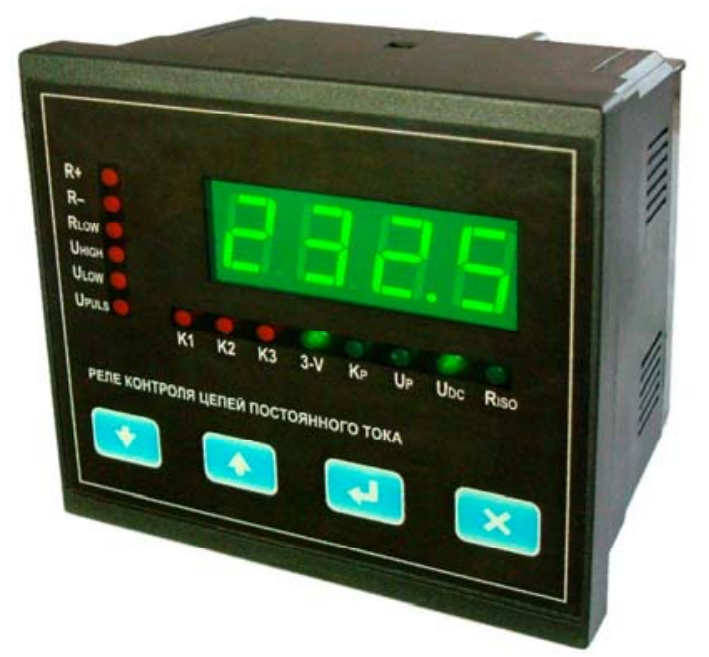

Fig. 7

Conclusions.

1. Thanks to simplicity voltmeter readouts methods of insulation resistance measurement are commonly applied in DC and AC DC IT networks. Their alternative are techniques based on imposition of test signal from an auxiliary voltage source.

2. Application of two or three voltmeter readouts methods causes variation of conductor-to-ground voltages. However the same effect is caused by devices exploiting imposition of test signals.

3 . There is presented a novel method of limiting operation time of devices exploiting two or three voltmeter readouts methods.

4. There is presented a modified method of two voltmeter readouts for $\mathrm{AC} / \mathrm{DC}$ networks. Its novelty consists in measurement of mean value of phase voltage at $\mathrm{AC}$ side of diode rectifier.

\section{REFERENCES}

1. Ivanov E., Diachkov A. How to measure correctly insulation resistance of electric systems? Electrical engineering news, 2002, no.1(13). Available at: http://www.news.elteh.ru/arh/2002/13/22.php (Accessed 12 September 2015). (Rus).

2. Olszowiec P. Insulation Measurement and Supervision in Live AC and DC Unearthed Systems. Lecture Notes in Electrical Engineering, 2nd edition. Springer, 2014. doi: 10.1007/978-3642-29755-7.

3. Olszowiec P. O wyznaczaniu napięć trójfazowych prostowników diodowych. Wiadomości Elektrotechniczne, 2015, vol.1, no.10, pp. 33-34. (Pol). doi: 10.15199/74.2015.10.8.

4. Ivanov E., Diachkov A. How to measure correctly insulation resistance of electric systems? Electrical engineering news, 2002, no.2(14). Available at: http://www.news.elteh.ru/arh/2002/14/26.php (Accessed 12 September 2015). (Rus).

5. Available at: http://www.elmech.pl/spis-produktow-2 (Accessed 25 May 2016). (Pol).

6. KDZ-3. System kontroli i lokalizacji doziemien. Available at: www.zprae.pl/download.php?file=pub/File/KDZ-3.pdf.

(Accessed 10 July 2015). (Pol).

7. Opara A. Zastosowanie ekstrapolacji nieliniowej w systemie pomiaru i lokalizacji doziemienia. Wiadomości Elektrotechniczne, 2016, vol.1, no.2, pp. 24-27. (Pol). doi: 10.15199/74.2016.2.5.

8. Rele kontrolia tsepei postoiannogo toka RKI-1. Tekhnicheskoe rukovodstvo po ekspluatatsii [The relay DC control circuits РКИ-1. Technical Manual]. Available at: http://srza.ru/uploads/catalog/srz rki.pdf (Accessed 22 September 2015). (Rus).

Received 13.08.2016

Piotr Olszowiec, MSc., Electrical Engineer,

Elporem i Elpoautomatyka Spółka z o.o.,

28-200 Staszow, ul. Wschodnia 10/51, Poland, phone +48606613976 ,

e-mail: olpio@o2.pl

How to cite this article:

Olszowiec P. Low voltage networks insulation monitoring with two and three voltmeter readouts methods. Electrical engineering \& electromechanics, 2016, no.5, pp. 64-67. doi: 10.20998/2074-272X.2016.5.11. 